\title{
A review study of contrastive analysis theory
}

\author{
Mohammad Hamad Al-khresheh * \\ Executive Director-Experts of Academic Excellence Research Centre, Jordan
}

\author{
Key Words \\ First language \\ Second language \\ Errors \\ Language learning \\ Acquisition
}

Received: 5 October 2016

Accepted: 25 October 2016

Published: 19 December 2016

\begin{abstract}
Therefore, this research paper aims at reviewing one of the most influential theories of second language acquisition, which is Contrastive Analysis theory, exploring and discussing its theoretical foundations along with assumptions and then elaborating on the achievements and limitations of this theory. This review study reveals that despite all the adverse criticism, Contrastive Analysis theory has proved to be one of the most significant studies ever made in describing systems of languages. It should also be noted that current research has revived interest in this theory as a complementary and necessary part of the theory of second language acquisition, one that cannot be ignored. Moreover, Contrastive Analysis theory remains an influential construct in the field of second language acquisition, using comparisons of languages to explain areas of difficulty for learners. Following such a theory may contribute to a better understanding of the acquisition process of second language structures.
\end{abstract}

(C)2016 All Author(s). Published by TAF Publishing.

\section{INTRODUCTION}

As most foreign or second language teachers (ESL/EFL hereinafter) will attest, and as classroom research indicates, the influence of the first language (L1 hereinafter) is either noticeably or subtly evident in the second language (L2 hereinafter) classroom (Sheen, 1996; Spada and Yasuyo, 2010; Spada et al. 2005; Al-khresheh, 2015). Nevertheless, for researchers the difficulty has been to disambiguate the interlingual influence from that of the multitudinous other cognitive, developmental, and learner-specific variables in acquisitional play. This carefully articulated approach was of course initially welcomed as it furnished a step-by-step framework for how such interlingual contrastiveness might be carried out.

Yet when its procedures and predictions were put under the lens, cracks in the framework became evident. First, opponents were able to show that Contrastive Analysis theory (CA hereinafter) not only over-predicted nonoccurrent errors but also under-predicted manifest errors. Second, errors were just as arguably traced to the developing nature of learners' intralingual system rather than to any supposed interlingual source. Third, learners from a variety of linguistic backgrounds displayed similar acquisition patterns suggesting that there was an equally important process of "creative construction", alongside any mechanisms of L2 habit formation (Lightbown and Nina, 2006). Minimally, the

\footnotetext{
${ }^{*}$ Corresponding author: Mohammad Hamad Al-khresheh

†Email: mohd_khresheh@yahoo.com
} 
result of such observations was the conclusion that classical contrastiveness could furnish only a complementary, but not an overarching mode of analysis for such a complex process.

The school of thought known as CA is arguably the offspring of mid-century behaviourism and American descriptivism. While behaviourists and descriptivists alike adhered to precepts of replicability and falsifiability, and whilst such scientism had an undeniable influence on second language acquisition (SLA hereinafter), classical contrastiveness is not entirely beholden to the precepts of either paradigm. Initially, the contention was that successful SLA essentially involved the re-wiring of L1 habits. In other words, familiar L1 processes could be modified in accord with behaviourist procedures such as schedules of positive and negative reinforcement, rote and associative learning, over-learning, habit ingraining and shaping, reward and punishment schedules, and environmental manipulation (Brown, 2006). Such behaviouristic learning came to be, rightly or wrongly, closely allied to L2 pedagogy when Lado introduced the Contrastive Analysis Hypothesis (CAH hereinafter) based on earlier descriptivist recommendations along these lines. The idea was that learners could be trained in the acquisition of new phonological, morphological, and syntactic habits most ideally if the L1 and the L2 could be systematically compared and contrasted in advance.

\section{THEORETICAL FOUNDATIONS}

CA was first developed by Charles Fries (1945) as an integral component of the methodology of FL teaching (Al-khresheh, 2013). It was noted that in learning a FL, the learner tended to bring with him the knowledge of the L1, and suggested that this should be taken into consideration in teaching the L2. So, the psychological foundation of CA is transfer theory, substituting the L1 for the prior learning and the L2 for the subsequent learning.

According to $\mathrm{CA}$, the most effective materials for teaching a $\mathrm{L} 2$ are those that are based upon a scientific description of the language to be learnt, carefully compared with a parallel description of the native language (NL hereinafter) of the learner. The best way to achieve this was to undertake a comparative analysis of L1 and L2. Given this, CA assumes that those elements that are similar to the NL will be simpler to the learner, and those that are different will be difficult. Therefore, it is recommended that pedagogical materials be designed which would address the target language (TL hereinafter) in a systematic fashion based on the predicted difficulty of structures as derived from CA.

It is believed that, carrying out ' $\mathrm{CA}$ ' as well as planning the fitting course outline and instruction materials is as a result of the effort put in by Lane as cited by (Ammar and Nina, 2006). Such analyses were envisioned to be carried out in terms of forms, meaning and distributions of linguistic and cultural units in both L1 and L2. Three major sources contributed to a general rationale for conducting CA studies: First, the observation by students of language contact of the phenomenon of interference. Such a phenomenon was defined by Weinrich as "those instances of deviation from norms of either language which occur in the speech of the bilinguals as the result of their familiarity with more than one language"(cited in Bowers, 2002, 186). The practical experience of teachers of FL and their identification of deviations attributed to the learner's mother tongue (MT hereinafter) provide the second source, whilst the learning theory of interference within L1 based on findings in psychology constitutes the third dimension.

Given the above rationale, CA can be viewed in terms of three separate approaches: First, the purely linguistic approach, which maintains that CA is nothing more than contrasting for the sake of contrasting and the new knowledge it might provide. The second approach, on the other hand, maintains that CA is capable of encompassing all the errors which occur in SLA. Finally, there is a third position somewhere between these two points 
of view that contends that $\mathrm{CA}$ has been relegated much too high a position in language learning in the past, and further, on its own merits. CA does not hold a legitimate position in the general scheme of language teaching.

\section{Theoretical Assumptions}

CA is founded on the assumption that L2 learners will tend to transfer the formal features of their L1 to their L2 utterances. Simply put, this notion of 'transfer' means carrying over the habits of the MT into the L2. It can be also defined as the influence of the learner's L1 on the acquisition of L2 (Al-khresheh, 2016). Transfer can be considered as an important part in language learning at all levels. It is considered as a language learning strategy used by FL/L2 learners in order to facilitate their language learning. Learners start learning L2/FL language by transferring some sounds and meanings (semantic transfer). They also transfer several rules and structures consisting of pragmatics and word order.

The CA hypothesis has been predominant in L2 learning theory with ramifications in pedagogy as well. There are two assumptions or versions of the hypothesis: strong and weak. Within the strong version of the paradigm, researchers believe that errors in L2 learning could be attributed to patterns in the NL. It was considered theoretically possible to predict what errors would be made by making a careful detailed comparison of a learner's L1 and L2. Differences would constitute potential sources of errors. The weak version is a model with an explanatory power as opposed to a predictive power: That is, it is claimed that researchers can look at errors once they have been combined and offer an explanation based on a CA of that area of grammar as to why those errors occurred (Mair, 2005).

Furthermore, the strong version of CA refers to areas of complexity in the TL, which are expected by comparing L1 and L2. The areas of contrast will then form the basis for teaching materials. In contrast, the weak version of CA attempts to account for observed errors by starting with classroom data and using the differences between the two linguistic systems to clarify the errors. According to Bell (1981), the strong version of this approach is not only a resource of exploring errors but also a method for expecting them. The weak version presumes that equipped with a $\mathrm{CA}$ of the language concerned, the teacher will have a comprehensible depiction of the trouble area even before the learner has started to learn it. (Al-khresheh, 2013). Given the above, it could be said that the strong version of CA involves the process of expecting the area of complexity in the TL by comparing the L1 and L2, and the areas of contrast, being then used as the centre of teaching materials. The expected problems or predictions, however, have been found to be inadequate. The move was then towards the weak version in which a comparison between L1 and L2 systems was made to explain errors after they had occurred, rather than to predict them. The weak version of CA hypothesis therefore seems to be closer to Error Analysis theory (EA hereinafter) in that both start with students' errors. Critics of CA argue that neither of these assumptions is valid. However, proponents of CA have never claimed that CA can necessarily predict all errors in L2 production. The list of problems resulting from comparing the FL with the NL should be regarded as hypothetical problems until concluding validation is accomplished by checking it against the real speech of learners. The weak version of the CA hypothesis does not assert that CA has any predictive power. Rather, it claims that CA can only identify errors resulting from L1 interference. Thus, Chao (2003) explains that the weak version of CA hypothesis requires the teacher to have adequate knowledge about the language so that he can address the difficulties in L2 learning. The weak version of CA hypothesis does have the same requirements as the strong version. Therefore, the approach used by the weak version, in theory, makes fewer demands on CA than the strong CA version does. The weak version uses the evidence provided by the lin- 
guistic interference and then uses this evidence to explain the similarities and differences between the two languages.

\section{Types of Transfer}

Language transfer is generally divided into two main categories: positive or negative. According to Gass and Larry (2001), positive transfer results in correct utterances and facilitates language learning. Basically, the learner's L1 might facilitate L2 learning. Lado $(1957,158)$ asserts that "The basic premise of CA hypothesis is that language learning can be more successful when the two languages - the native and the foreign - are similar". Nevertheless, negative transfer results with incorrect outcomes. It results in deviations from the TL. Al-khresheh (2013) points out that there are four types of divergences that are caused by differences between NL and TL. They can be summarised as follows:

1. Overproduction: learners produce a given $\mathrm{L} 2$ structure with much greater occurrence than natives of L2 do. They can often be as a result of underproduction. Instead, learners make extreme use of what they suppose to be correct and acceptable; consequently, resulting in overuse of certain words or structures.

2. Underproduction (or avoidance): learners produce hardly any or no examples of L2 structure. They can often be caused by conscious avoidance of complex L2 structures.

3. Misinterpretation: This type of errors occurs when L1 structures influence the interpretation of L2 messages.

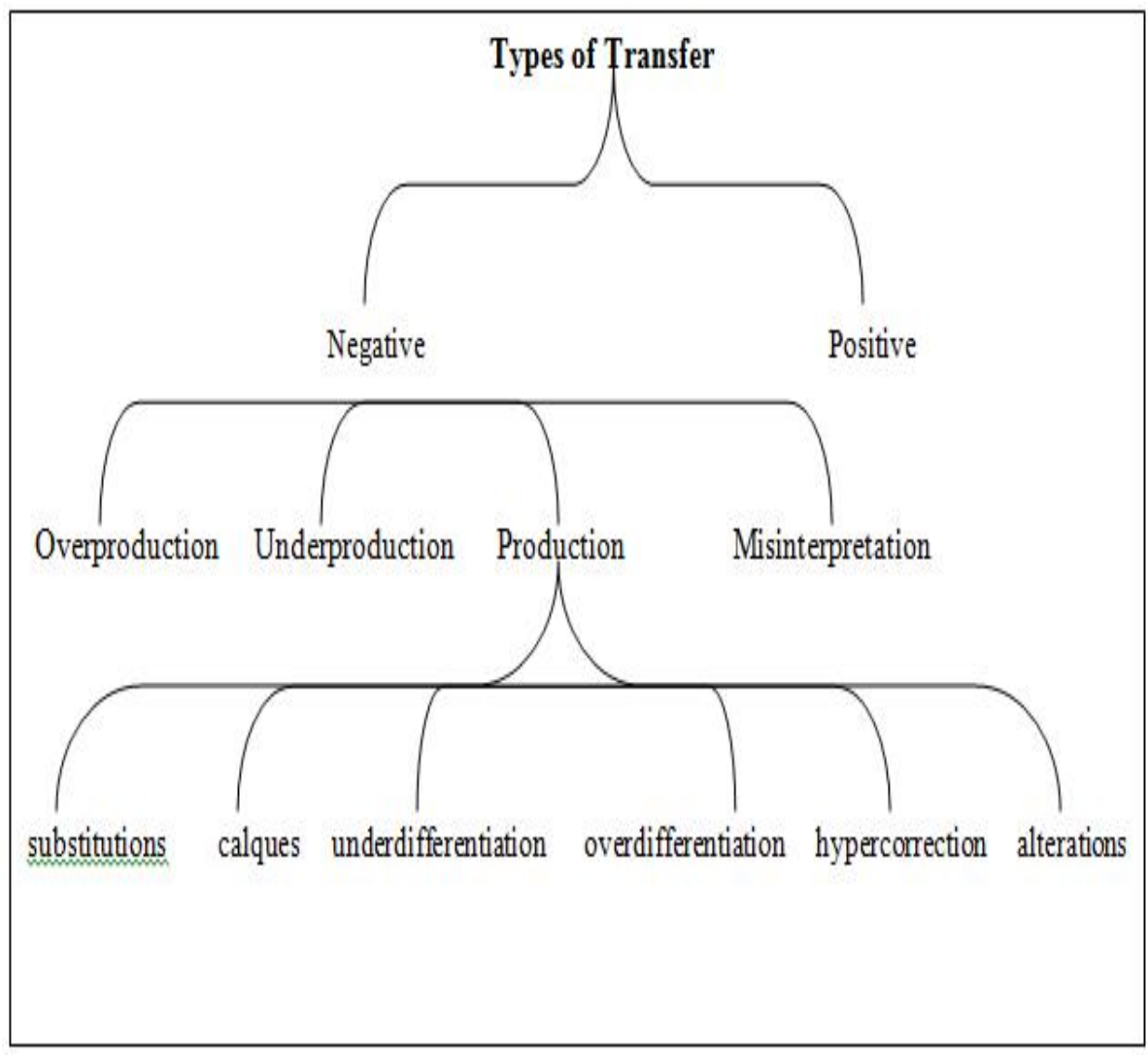

FIGURE 1. Types of transfer

4. Production: This type of errors can be classified into six categories: substitutions (i.e. think is pronounced as /fink/ in Poland and /sink/ in Egypt, people as /beoble/ in Ara- 
bic, love as /laugh/ in Saudi Arabia, fish as /fis/ in Malaysia, and thirty as /dirty/ in India),calques, under-differentiation, over-differentiation, hypercorrection and alterations of structures. According to Odlin $(2003,37)$, calques, substitutions and alterations of structures compose most forms of production errors. Figure 1 below illustrates types of transfer.

The above diagram shows that there are various types of negative transfer errors that language learners may commit when they fall back on their L1. L2 learners might make use of their knowledge of the L1 to help them in learning and using other languages. However, this is only limited for those structures that are quite similar to each other. Generally, the role of transfer starts diminishing gradually as learners get more experience with mastering the TL.

\section{Investigating L2 Errors}

An awareness of the "pull of MT" phenomenon in SLA can be traced back to the nineteenth century where it was documented in the writings of such linguists as Harold Palmer, Henry Sweet, and Otto Jespersen. It was Fries, however, who expressed this awareness in more practical terms: "The most efficient materials are those that are based upon a scientific description of the language to be learnt, carefully compared with a parallel description of the native language of the learner" Fries (cited in Sheen, 1996). In this statement, then, lies the roots of CA which was later developed by Lado, that $\mathrm{L} 2$ learners tend to transfer the characteristics of their NL into the FL and thus start making errors. The learners transfer the forms and meaning of their NL and culture productively when attempting to speak the FL (Bowers, 2002). These two statements are often quoted to show the need for CA in teaching and learning a FL.

According to Gass and Larry $(2001,72)$, "contrastive analysis is a way of comparing languages in order to determine potential errors for the ultimate purpose of isolating what needs to be learnt and what does not need to be learnt in a SLL situation". They discuss the two positions of CA, which they call "predictive" and "explanatory", and "strong" and "weak" version, respectively. James (2005) discusses the differences between the strong and the weak versions of CA. He explains that the strong version claims to be able to predict errors, whilst the weak one claims to be able to diagnose the errors after they have been made. However, he does not believe in the two versions, but states that CA is always predictive, whereas the job of diagnosing errors after they have been made belongs to Error Analysis (EA). So, it could be understood that CA must be done prior to EA, in order to avoid problems with error-identification and to know what errors to attribute to negative transfer. James (1998) also explains the differences between theoretical CA and applied $\mathrm{CA}$, and claims that theoretical CA is static, whilst applied CA is unidirectional. Briefly, CA assumes that L2 learners' errors are the result of negative interference from the NL. Accordingly, CA predicts errors before they happen and it tries to eliminate them by focusing the instruction on the areas of differences. Figure 2 below illustrates the procedure of this approach.

Given the above diagram, CA is defined as a pedagogical procedure which explains errors committed by L2 learners by comparing between the two systems of the TL and NL of the learners. In other words, CA can also be defined as a linguistic comparison of the structures of two or more languages so as to demonstrate their differences and similarities. It stipulates that when the L1 and L2 are different, learning might be relatively unsuccessful or difficult. 


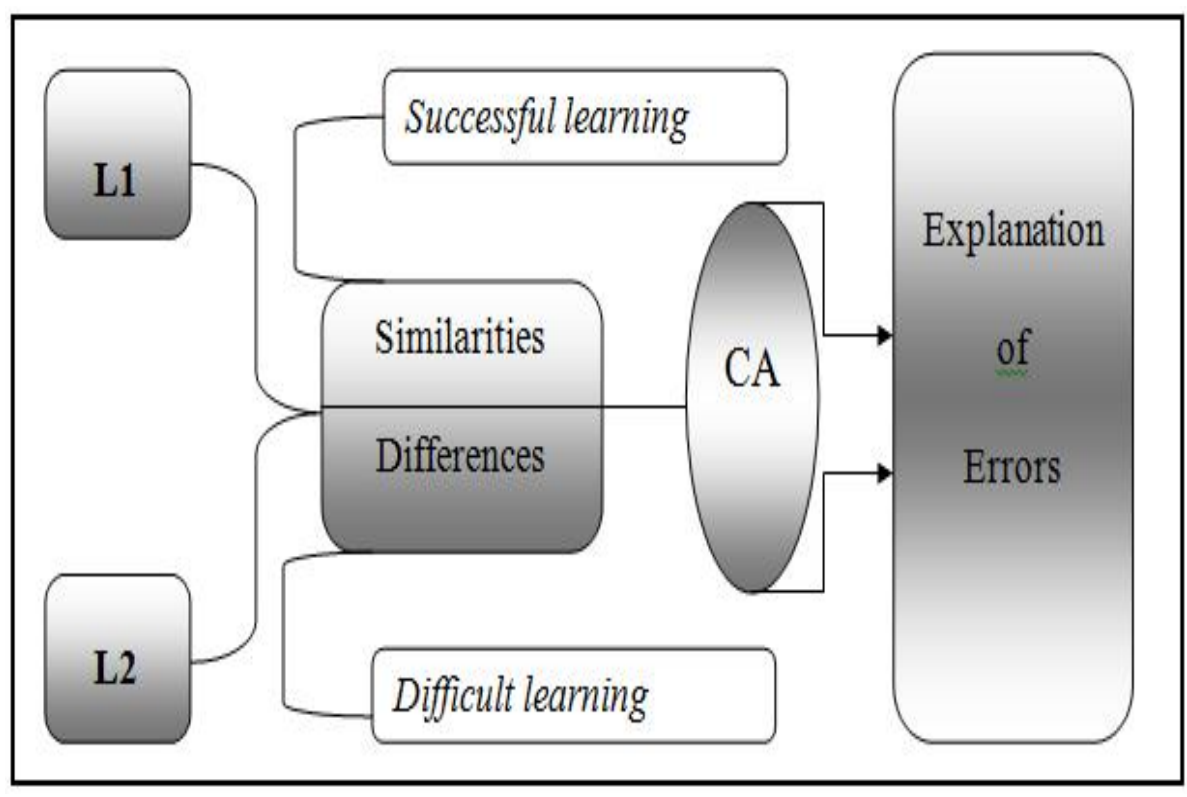

FIGURE 2. The procedure of CA

\section{Steps for Contrastive Analysis}

As mentioned earlier, CA can be used to understand the differences as well as the similarities between the learner's NL and the TL. Knowledge of the similarities and differences can be of great help in understanding L2 errors. Therefore, following the CA gives a great systemic description to the both languages (L1 \& L2).

CA can be broken down to a set of component procedures. The five steps for making a systematic comparison and contrast of any two languages are: Selection - description comparison - prediction - verification. The first step is to select or take the two languages, L1 and L2, and writing formal descriptions of them (or choosing descriptions of them). Writing a formal description needs choosing a special theoretical model which can be traditional, structural or transformational. In this step, there is a need to decide what is to be contrasted/compared with what. That is because it is quite difficult to compare everything (sound, word, structure...etc) so the analysis should be limited to a specific category. Once the selection is done, the selected linguistic units/structures can be described. This step is called 'description'. The two languages should be linguistically described within the same theory which is CA. The main focus should be on the differences. Third, having described the linguistic-selected units, it is crucial to compare the structures with each other. This step is called 'comparison'. In this step, the differences and similarities can be compared in form or meaning. Here, the term 'form' refers to any linguistic unit of any size. It is impossible to clearly compare the two languages without giving a full description.

Step four is 'prediction'. It is about making a prediction of difficulty through the contrast. The CA can noticeably predict for the similarities and differences of the two compared languages. Based on the researcher's knowledge, he/she can judge if the differences and similarities are problematic or not. To clearly describe the prediction step, Stockwell et al. (1965) proposed a 'hierarchy of difficulty' based on the notions of transfer (positive, negative, and zero) and of optional and obligatory choices of certain linguistic units in the two languages in contrast. When the structures of the given two languages are similar, positive transfer will occur whilst with those that are different, a negative transfer will take place. Where there is no relation between those structures of the two languages, zero 
transfer will occur. The following criteria can be used to establish the 'preferred pedagogical sequence': (1) hierarchy of difficulty (2) functional load (3) potential mishearing (4) pattern congruity. Finally, the last step of CA is 'verification'. Here, the researcher should find out whether the predictions given in the previous step (prediction) are true or not.

\section{CONCLUSION}

In spite of the initial enthusiasm shown for CA, its value has been questioned by numerous scholars working in applied linguistics. Johansson $(1973,77)$, for example, reports that: (1) CA is not necessary since teachers are interested in knowing difficulties rather than theoretical predictions. (2) The requirements of CA have not been adequately met. It provides no formal way of determining which elements of one language are to be compared with those of the other. (3) CA cannot account for everything within its domain since, for example, it cannot formally indicate which of these differences will lead to difficulties and which will not.

Moreover, recent studies have revealed that CA is most predictive at the phonological level and least predictive at the syntactic level because no language has been adequately compared yet to another language, and what is predicted as a difficulty by the CA hypothesis is not always so in practice.

In spite of past criticism, it should be noted that current research has revived interest in CA as a complementary and necessary part of the theory of SLA, one that cannot be ignored. CA comprises a series of statements about the differences and similarities between two languages. There has always been a component of CA in FL teaching. Some thirty years ago, it was highly believed that FL learning contained mainly, if not exclusively, in learning the contrast between L1 and L2. Today, CA is being reassessed, and its applicability to language teaching is viewed in a different light.

CA has been widely used for constructing the previous studies' theoretical framework. Adopting CA theory by some of the latest studies is a good indicator to its effectiveness in describing L2 learners' errors especially those which can be due to interference from the MT. There are numerous studies that show the effectiveness of the CA. According to these studies, the knowledge about the kinds and degree of differences and similarities between languages on a number of linguistic levels helps in the process of predicting possible difficulties faced by L2 learners (Al-Jarf, 2000; Al-Khresheh, 2010, 2011, 2016; Al-Ta'ani, 1986; Elewa, 2004; Faghih, 1997; Gilquin and Magali, 2008; Kharma, 1983; Kharma and Ali, 1989). From the pedagogical perspective, it could be revealed that CA helps students to see clearly some of the problems they might face. They may avoid making interlingual errors if they are completely aware of the possible difficult areas. CA provides an access for EFL/ESL teachers to diagnose their students' errors. Teachers may not expect students' errors in advance, but at least they can have the ability to explain or diagnose students' errors through CA. Identification of differences and similarities between languages might have a great contribution to the linguistic theory. This fact has been clearly acknowledged by several researchers, such as (Al-khresheh, 2015, 2006; Chao, 2003; Matter, 1999), who declared that it might be helpful to compare L1 and L2 in the classroom to highlight differences and similarities. Therefore, CA remains an influential construct in the field of SLA; using comparisons of languages to explain areas of difficulty for learners. Following CA may contribute to a better understanding of the acquisition process of English L2 structures.

It could be said that one of the undoubted merits of $\mathrm{CA}$ is the fact that it offered a natural, even if only partial explanation to the errors committed by L2/FL learners. CA regarded most errors to be the effect of a phenomenon of interlingual interference, when patterns 
existing in the learner's L1 were transferred as such into his/her use of the language to be learnt. Viewed from this standpoint, EA had no appropriate status; it was a mere addition to CA. Besides, the main purpose of CA studies "is not only a better understanding of the linguistic structure, but also applied deductions, meant to raise the entire teaching activity above the empirical and occasional practice, to outline fundamental teaching programs based on the scientific knowledge of the language" (Mihalache, 2004, 28).

To conclude, CA should rest on language universals; otherwise, there is only arbitrariness in the surface manifestation of the contrast. The purpose of CA, then, is to show that universal deep structures manifest themselves in surface structures via transformational rules. At that level, transformational rules must be contrasted to see where the problem areas will appear. CA can be of importance even to the theoretical linguist who looks for some support for his theory of language.

\section{LIMITATIONS AND RECOMMENDATIONS}

Researchers in SLA still maintain the position that CA can contribute to 'translation theory', language typology, the description of particular languages and the study of language universals. Pedagogically, in the field of SLA, the language behaviour change that needs to take place in the ESL student is equal to the structure difference between NL and TL of the student. Thus, it is the job of the sociologist, the linguist and the cultural anthropologist to identify these differences in the NL and FL. Once the differences have been identified, it is the job of the FL teaching program writer to develop such materials that can help students reduce these differences. Furthermore, it is the job of the teacher to be aware of these differences so that he/she is better prepared to teach the language.

\section{ACKNOWLEDGEMENTS}

With my deepest feelings I heartily dedicate this work to the soul of my late father, the one who sacrificed so much to help me continue my education and whose patience and support motivated me to work harder and accomplish more. May Almighty Allah bless his soul and grant him the highest levels of paradise. To my lovely father, With Love, Great Respect and Eternal Appreciation

\section{REFERENCES}

Al-Jarf, Reima. 2000. Grammatical agreement errors in L1/L2 translations. International Review of Applied Linguistics in Language Teaching 38, no. 1: 1-15. DOI: 10.1515/iral.2000.38.1.1

Al-khresheh, Mohammad H. 2010. Interlingual interference in the English language word order structure of Jordanian EFL learners. European Journal of Social Sciences 16, no. 1: 106-113.

Al-khresheh, Mohammad H. 2011. An investigation of interlingual interference in the use of 'and' as a syntactic coordinating structure by Jordanian EFL learners. European Journal of Social Sciences 18, no. 3, 426-433.

Al-khresheh, Mohammad H. 2013. The misuse of word order in the writing of Jordanian EFL Learners. Unpublished doctoral dissertation, University of Malaya, Kuala Lumpur, Malaysia.

Al-khresheh, Mohammad H. 2006. The interlingual transfer of Arabic in the English writings of Arab EFL students. Pa- per presented at the Second International Language Learning Conference, USM-Penang, Malaysia.

Al-khresheh, Mohammad H. 2015. A review study of interlanguage theory. International Journal of Applied Linguistics \& English Literature 4, no. 3, 124-131.

Al-khresheh, Mohammad H. 2016. A review study of error analysis theory. International Journal of Humanities and Social Science Research 2: 49-59.

Al-Ta'ani, Muhammad HA. 1986. An investigation of secondary school students' errors in formulating wh-questions. Unpublished MA thesis, Yarmouk University, Irbid, JO. 
Ammar, Ahlem, and Nina Spada. 2006. One size fits all? Recasts, prompts, and L2 learning. Studies in Second Language

Acquisition 28, no. 4: 543-574. DOI: 10.1017/S0272263106060268

Bell, Roger T. 1981. An introduction to applied linguistics: Approaches and methods in language teaching. London, UK:

Batsford Academic and Educational.

Bowers, John. 2002. Transitivity. Linguistic Inquiry 33, no. 2: 183-224. DOI: 10.1162/002438902317406696

Brown, H. Douglas. 2006. Principles of language learning and teaching, 5th ed. New York, NY: Pearson Education Lim- ited.

Chao, Yu-Chuan J. 2003. Contrastive rhetoric, lexico-grammatical knowledge, writing expertise, and metacognitive

knowledge: An integrated account of the development of English writing by Taiwanese students. Unpublished doc- $\quad$ toral dissertation, University of Auckland, Auckland, NZ.

Elewa, Abdel-Hamid. 2004. Collocation and synonymy in classical Arabic: A corpus-based study. Unpublished doctoral

thesis, Institute of Science and Technology (UMIST), University of Manchester, Manchester, UK.

Faghih, Esmail. 1997. A contrastive analysis of the Persian and English definite articles. International Review of Applied

Linguistics in Language Teaching 35, no. 2: 126-237.

Gass, Susan M., and Larry Selinker. 2001. Second language acquisition: An introductory course, 2nd ed. London, UK:

Lawrence Erlbaum Associates.

Gilquin, Gaëtanelle, and Magali Paquot. 2008. To o chatty: Learner academic writing and register variation. English Text

Construction 1, no. 1: 41-61. D0I: 10.1075/etc.1.1.05gil

James, Carl. 1998. Errors in language learning and use: Exploring error analysis. London, UK: New York: Longman. James, Carl. 2005. Contrastive analysis and the language learner. In Linguistics, language teaching and language learnDavid J. Allerton, Cornelia Tschichold and Judith Wieser, eds., 1-20, Basel, CH: Schwabe.

Johansson, Stig. 1973. Papers in contrastive linguistics and language Testing. Lund, SE: Gleerup.

Kharma, Nayef N. 1983. Studies in descriptive linguistics: A contrastive analysis of the use of verb forms in English and

Arabic. Heidelberg, DE: Juliuss Groos Verlag.

Kharma, Nayef N., and Ali H. Hajjaj. 1989. Use of the mother tongue in the ESL classroom. International Review of Applied

Linguistics 27, no. 3: 223-235.

Lado Robert. 1957. Language teaching: A scientific approach. New York, NY: McGraw Hill.

Lightbown, Pasty M., and Nina Spada. 2006. How languages are learned, 5th ed. Oxford, UK: Oxford University Press.

Mair, C. 2005. Recent Advances in contrastive linguistics and language typology: The spin-off for language teachers. In

Linguistics, language teaching and language learning, David J. Allerton, Cornelia Tschichold, and Judith Wieser, ed., 21-39. Basel, CH: Schwabe AG.

Mattar, Hameed. 1999. Translation elicitation techniques and mother-tongue interference: Any significant connection?

In- $\quad$ ternational Review of Applied Linguistics in Language Teaching 37, no. 4: 307-321.

Mihalache, Roxana. 2005. Contrastive analysis and error analysis-Implications for the teaching of English. Language

Teaching Forum 44, no. 4: 28.

Odlin, T. 2003. Language Transfer. Shanghai, CN: Shanghai, China: Shanghai Foreign Language Education Press.

Sheen, Ronald. 1996. The advantage of exploiting contrastive analysis in teaching and Learning a foreign language. Inter- $\boldsymbol{n a -}$ tional Review of Applied Linguistics in Language Teaching 34, no. 3: 183-198. DOI: 10.1515/iral.1996.34.3.183

Spada, Nina, and Yasuyo To mita. 2010. Interactions between type of instruction and type of language feature: A meta- Analysis. Language Learning 60, no. 2: 263-308. DOI: 10.1111/j.1467-9922.2010.00562.x

Spada, Nina, Pasty M. Lightbown, and Jaonna L. White. 2005. The importance of form/meaning mappings in explicit form- focused instruction. In Investigations in instructed second language acquisition, eds., Housen, Alex, and Michel Pier- rard, 199-234. Amsterdam, The Netherlands: Mouton de Gruyter.

Stockwell, Robert P., Donald Bowen J., and John W. Martin. 1965. The grammatical structures of English and Spanish.

Chicago, IL: University of Chicago Press.

— This article does not have any appendix. - 